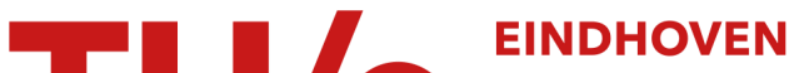 UNIVERSITY OF TECHNOLOGY
}

\section{Fuel reduction of parallel hybrid electric vehicles}

Citation for published version (APA):

Koot, M. W. T., Kessels, J. T. B. A., \& Jager, de, A. G. (2005). Fuel reduction of parallel hybrid electric vehicles. In Proceedings of the 2005 IEEE Vehicle Power and Propulsion Conference (VPPC 2005), 7-9 September, 2005, Chicago, USA (pp. 99-104). Institute of Electrical and Electronics Engineers.

https://doi.org/10.1109/VPPC.2005.1554527

DOI:

10.1109/VPPC.2005.1554527

Document status and date:

Published: 01/01/2005

Document Version:

Publisher's PDF, also known as Version of Record (includes final page, issue and volume numbers)

Please check the document version of this publication:

- A submitted manuscript is the version of the article upon submission and before peer-review. There can be important differences between the submitted version and the official published version of record. People interested in the research are advised to contact the author for the final version of the publication, or visit the $\mathrm{DOI}$ to the publisher's website.

- The final author version and the galley proof are versions of the publication after peer review.

- The final published version features the final layout of the paper including the volume, issue and page numbers.

Link to publication

\section{General rights}

Copyright and moral rights for the publications made accessible in the public portal are retained by the authors and/or other copyright owners and it is a condition of accessing publications that users recognise and abide by the legal requirements associated with these rights.

- Users may download and print one copy of any publication from the public portal for the purpose of private study or research.

- You may not further distribute the material or use it for any profit-making activity or commercial gain

- You may freely distribute the URL identifying the publication in the public portal.

If the publication is distributed under the terms of Article $25 \mathrm{fa}$ of the Dutch Copyright Act, indicated by the "Taverne" license above, please follow below link for the End User Agreement:

www.tue.nl/taverne

Take down policy

If you believe that this document breaches copyright please contact us at:

openaccess@tue.nl

providing details and we will investigate your claim. 


\title{
Fuel Reduction of Parallel Hybrid Electric Vehicles
}

\author{
Michiel Koot*, J.T.B.A. Kessels, and Bram de Jager \\ Technische Universiteit Eindhoven \\ P.O. Box 513, 5600 MB Eindhoven, The Netherlands \\ * corresponding author:m.w.t.koot@tue.nl
}

\begin{abstract}
This paper compares the benefits of two parallel drivetrain configurations with an Integrated Starter Generator (ISG): one with the ISG connected directly to the engine, and one with the ISG connected to the drivetrain, after the clutch. Both configurations include Start-Stop operation, but only the latter one can turn off the engine during propulsion. The effect on fuel economy is analyzed by simulations using optimization over a given driving cycle. Results show that with the latter configuration a much higher fuel reduction can be obtained.
\end{abstract}

Keywords - Hybrid electric vehicles, energy management, fuel reduction, mixed integer optimization

\section{INTRODUCTION}

The drivetrain of a conventional vehicle can easily be modified to look like a parallel hybrid electric vehicle (HEV) by replacing the alternator with an Integrated Starter Generator (ISG). The possibility to change the operating point of the engine and to turn it off, gives rise to a reduction of fuel consumption and exhaust emissions.

This paper analyzes the benefits of two parallel drivetrain configurations: one with the ISG connected directly to the engine, before the clutch, and one with the ISG connected directly to the drivetrain, after the clutch. The first configuration can only turn off the engine during standstill and deceleration. The second configuration offers the opportunity to turn off the engine during propulsion.

The effect on fuel economy is analyzed by using optimization over a given driving cycle. The optimization problem is formulated as a Linear Programming (LP) problem [1]. Adding Start-Stop functionality makes it a Mixed Integer LP (MILP). A similar approach is applied to a series HEV without Start-Stop in [2]. Another formulation is a Dynamic Program [3] as done, e.g., in [4], [5]. Here, LP is chosen because of its easy implementation and fast computation.

This research continues on previous work [6], [7], that focussed on energy management of vehicles with a conventional drivetrain.

This paper is built up as follows. The vehicle topology will be described and analyzed in Section II. The objective is presented in Section III. Section IV presents the vehicle model. In Section V, the energy management control problem is formulated and solved as an optimization problem. The performance will be evaluated by simulations in Section VI. Conclusions are given in Section VII.

\section{Parallel Hybrid Electric Vehicle}

The drivetrain of a parallel HEV is based on a conventional vehicle, where the alternator is replaced by an Integrated Starter Generator (ISG) that can also be used for propulsion. The clutch can be located before or after the power split for the ISG. If the clutch is closed, the configurations are similar.

For this case study, it is assumed that the vehicle speed is defined by the driver and that the gear ratio is selected by either the driver or by the automatic transmission. This way, the engine speed is also predefined.

\section{A. Power flow description}

The power flow in the vehicle when the clutch is closed is shown in Fig. 1. The power required for the drivetrain is delivered by the engine, the ISG, and the brakes. The internal combustion engine converts fuel into mechanical power. The ISG converts mechanical power into electric power or vice versa. The electric side of the ISG is connected to the battery and the auxiliary electric load. The battery can be separated in the (dis)-charging losses and the net energy storage.

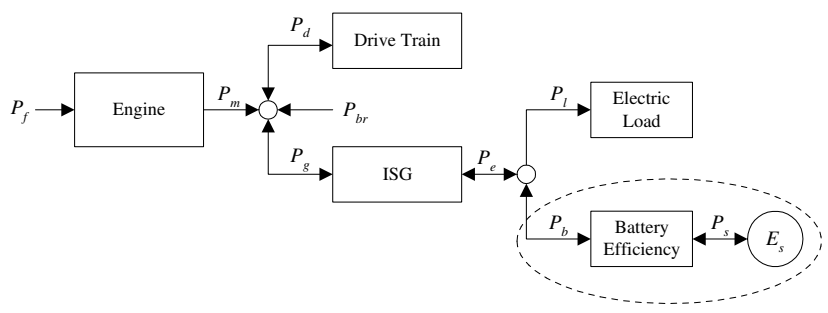

Fig. 1. Power flow in a vehicle

\section{OBJECTIVE}

Hybrid Electric Vehicles require an energy management strategy to control the power flow in an optimal way, meaning that fuel consumption and emissions are reduced while maintaining requirements on performance and comfort.

In this paper, the difference in fuel reduction depending on the location of the clutch is being evaluated. To do so, the control objective is to minimize the fuel consumption for a given driving cycle. This can be described as an optimization problem:

$$
\min _{x} J(x) \quad \text { subject to } \quad G(x) \leq 0
$$


The cost function $J$ expresses the fuel use over a driving cycle as function of the design variables $x$. This way, the characteristics of all components can be combined into a single cost function over a time interval $\left[0, t_{e}\right]$ :

$$
J(x)=\int_{0}^{t_{e}} P_{f}(x(t)) \mathrm{d} t
$$

where $P_{f}$ represents the fuel rate.

The operating range of the components is limited, so bounds have to be set on their power and energy levels. To prevent the storage device from being drained, an endpoint constraint on the state of charge (SOC) can be used.

The dynamics are modeled in discrete time and the component losses are modeled using piecewise linearities. This way, the nonlinear optimization problem reduces to a linear programming problem:

$$
\min _{x} J(x)=h^{T} x \quad \text { subject to } \quad A x \leq b
$$

Piecewise linear functions of the form:

$$
x=\max \left(a_{i} y+b_{i}\right) \quad i=1, \ldots, m
$$

can be incorporated in a LP by adding secondary variables $y$ together with inequality constraints:

$$
\min _{x} h^{T} x \quad \text { subject to } \quad x \geq a_{i} y+b_{i}
$$

If the objective is monotonically increasing with $x$, so $h>0$, $x$ will always be pushed on one of the constraints.

\section{Modeling}

The control problem has been described as an optimization problem. Here, the relation between the design variables and the cost function is described which is needed to compute the solution.

\section{A. Components}

For the energy storage level, a discrete linear integrator model is used:

$$
E_{s}(k)=E_{s}(k-1)+P_{s}(k) \Delta t
$$

or equivalently:

$$
E_{s}(k)=E_{s}(0)+\sum_{i=1}^{k} P_{s}(i) \Delta t
$$

The state of charge $(S O C)$ is the relative energy level:

$$
S O C=\frac{E_{s}}{E_{c a p}} \cdot 100 \%
$$

where $E_{c a p}$ is the energy capacity of the battery.

The (dis)-charging of the battery can be modeled as follows:

$$
P_{b}=\max \left(\frac{1}{\eta_{c}} P_{s}, \eta_{d} P_{s}\right)
$$

where $P_{b}$ represents the power entering or leaving the battery terminals, and $P_{s}$ represents the power actually stored in the battery. $\eta_{c}$ is the charge efficiency, and $\eta_{d}$ the discharge efficiency. A typical curve is shown in Fig. 2.

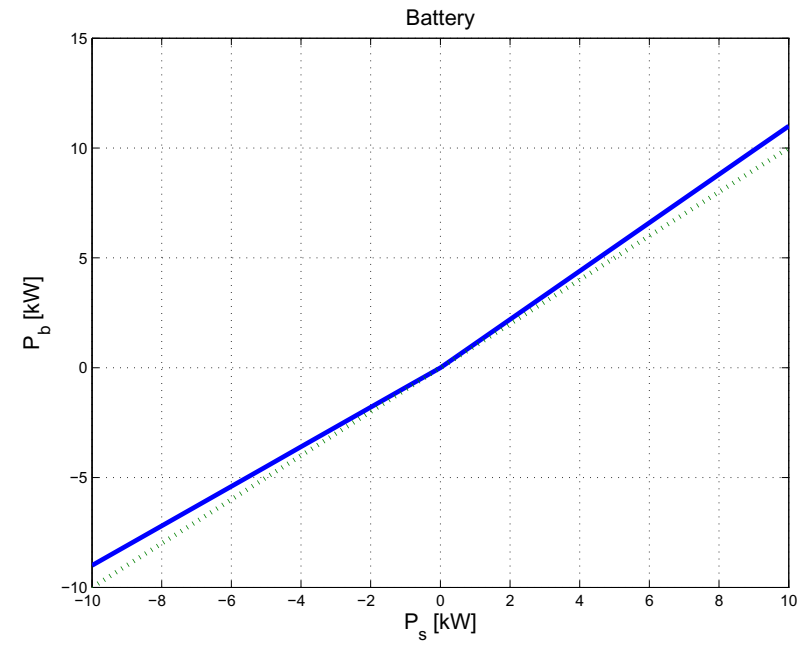

Fig. 2. Battery characteristic

The characteristic of the ISG is given by a nonlinear relation, that can be approximated piecewise linearly:

$$
P_{g}=g_{0}(w)+\max \left(\frac{1}{\eta_{g}} P_{e}, \eta_{m} P_{e}\right)
$$

where $g_{0}$ is the friction loss, $\eta_{g}$ is the conversion efficiency in generator mode $\left(P_{e}>0\right)$, and $\eta_{m}$ the conversion efficiency in motor mode $\left(P_{e}<0\right)$. A typical curve is shown in Fig. 3.

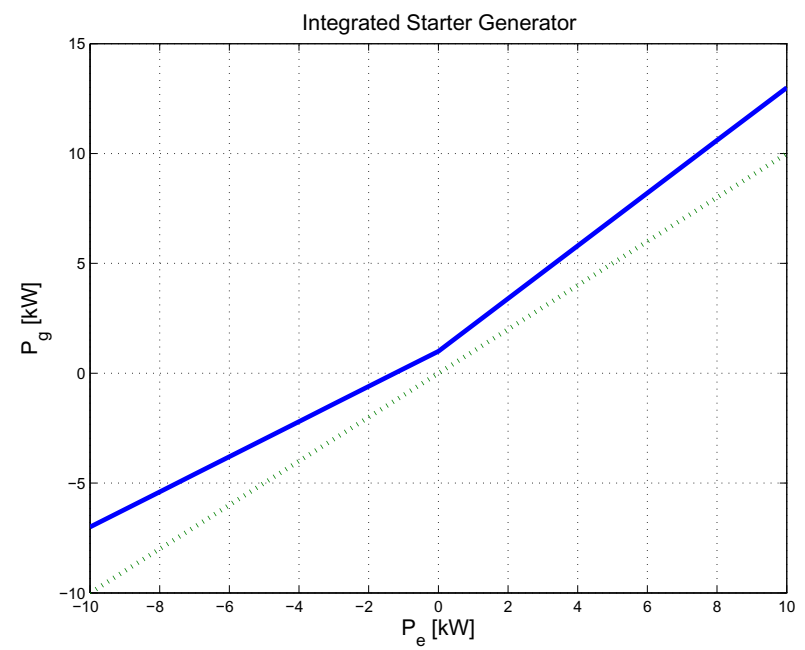

Fig. 3. ISG map

The characteristic of the fuel converter is given by the following relation:

$$
P_{f}=f\left(P_{m}, \omega\right)
$$

where $P_{m}$ is the mechanical power and $\omega$ the engine speed. A typical curve for a given engine speed $\omega$ is shown in Fig. 4. The fuel use is positive for zero power, due to friction. This can be avoided by turning off the engine during idle, which is called Start-Stop. 
Assuming the fuel map is convex, it can be described using $m$ linear approximations, such that:

$$
P_{f} \approx \max \left(f_{01}+f_{11} P_{m}, \ldots, f_{0 m}+f_{1 m} P_{m}\right)
$$

where the coefficients $f_{0 i}, f_{1 i}$ depend on $\omega$.

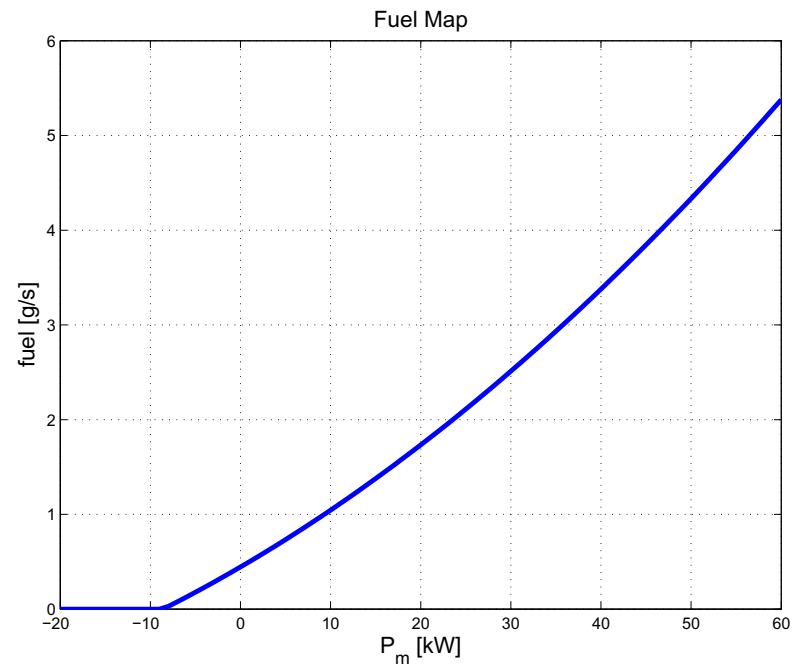

Fig. 4. Fuel map

\section{B. Drivetrain}

For a given vehicle speed profile $v(t)$ and selected gear ratio $g_{r}(t)$, the corresponding engine speed and torque needed for propulsion can be calculated using the following formulas:

$$
\begin{aligned}
\omega(t) & =\frac{f_{r}}{w_{r}} g_{r}(t) v(t) \\
F_{d}(t) & =M \dot{v}(t)+\frac{1}{2} \rho C_{d} A_{d} v(t)^{2}+M g C_{r} \\
\tau_{d}(t) & =\frac{w_{r}}{f_{r}} \frac{1}{g_{r}(t)} F_{d}(t) \\
P_{d}(t) & =\omega(t) \tau_{d}(t)
\end{aligned}
$$

The parameters are explained in Table I.

TABLE I

\section{PARAMETER EXPLANATION}

$\begin{array}{llll}\text { Symbol } & \text { Quantity } & \text { Symbol } & \text { Quantity } \\ M & \text { Vehicle mass } & w_{r} & \text { Wheel radius } \\ A_{d} & \text { Frontal area } & f_{r} & \text { Final drive ratio } \\ C_{d} & \text { Air friction coefficient } & g & \text { Gravity } \\ C_{r} & \text { Rolling resistance } & \rho & \text { Air density }\end{array}$

\section{Power flow}

The electric power flow equation is given by:

$$
P_{e}=P_{l}+P_{b}
$$

The mechanical power flow equation is given by:

$$
P_{m}=P_{d}+P_{g}+P_{b r}
$$

where $P_{b r} \geq 0$ is the power dissipated by the friction brakes. $P_{m \min }(\omega)$ is the friction in the engine at zero fuel use. At moments where:

$$
P_{d}<P_{m \text { min }}-g_{0}
$$

electric power can be generated without fuel use. This is called regenerative braking. It is assumed that the friction brakes are only used at moments when:

$$
P_{d}<P_{m \min }-P_{g \max }
$$

\section{Start-Stop operation}

\section{Configuration I}

First the case where the ISG is connected directly to the engine is considered.

If the engine is turned off, this means that:

$$
P_{e}=0 \quad P_{g}=0 \quad P_{m}=0 \quad P_{f}=0
$$

which results in:

$$
\begin{aligned}
& P_{b}=-P_{l} \\
& P_{d}=-P_{b r}
\end{aligned}
$$

Because $P_{b r} \geq 0$, the engine can only be turned off when $P_{d} \leq 0$ and if the electric load can be delivered by the battery. It is only advantageous to do so, if the additional fuel for restarting the engine and for recharging the battery during propulsion is smaller than the fuel saved during stand still.

Start-Stop can be included by introducing a binary variable $S$, where $S=1$ means the engine is running, and $S=0$ means the engine is turned off.

This can be achieved with the following constraints:

$$
\begin{aligned}
S P_{e \min } & \leq P_{e} \leq S P_{e \max } \\
S P_{\min } & \leq P_{m} \leq S P_{\operatorname{mmax}}
\end{aligned}
$$

Normally, the engine characteristics are such that $P_{m}=0$ corresponds to $P_{f}>0$ and $P_{f}=0$ to $P_{m}<0$, but if the engine is turned off, the operating point becomes $P_{m}=0$ and $P_{f}=0$. Therefore, the engine model is changed into:

$$
P_{f} \geq f_{0 i} S+f_{1 i} P_{m}
$$

such that $S=0$ yields that $P_{f}=0$ for $P_{m}=0$.

Equivalently, the alternator model is changed into:

$$
P_{g}=g_{0} S+\max \left(\frac{1}{\eta_{g}} P_{e}, \eta_{m} P_{e}\right)
$$

These constraints are still linear in the design variables.

\section{Configuration II}

If the ISG is connected directly to the drivetrain, or after the clutch, the ISG can still be operated when the clutch is opened and the engine is turned off, which means that:

$$
P_{m}=0 \quad P_{f}=0
$$

which results in:

$$
P_{d}=-P_{g}-P_{b r}
$$


Because $P_{g}$ can be both positive and negative, the engine can be turned off whenever the maximum ISG power in motor mode is sufficient to propel the vehicle.

This can be achieved with the following constraints:

$$
\begin{gathered}
S P_{m \min } \leq P_{m} \leq S P_{m \max } \\
P_{f} \geq f_{0 i} S+f_{1 i} P_{m}
\end{gathered}
$$

\section{Penalty}

To prevent frequent switching of the engine, both configurations require a penalty cost for starting the engine. This is implemented using an additional variable $R$ as follows:

$$
R(k)=\max (S(k)-S(k-1), 0)
$$

The cost criterium is modified to:

$$
J(x)=\sum_{k=1}^{n}\left(P_{f}(x(k)) \Delta t+C R(k)\right)
$$

such that, for every time the engine is started, a cost $C$ is added to the fuel consumption.

\section{OptIMIZATION}

The energy management problem is formulated as a Linear Programming problem. Adding Start-Stop functionality makes it a Mixed Integer LP because $S$ is a binary variable.

\section{A. Cost function}

The complete set of design variables becomes:

$$
x=\left[\begin{array}{lllllllll}
P_{s} & P_{b} & P_{e} & P_{g} & P_{b r} & P_{m} & P_{f} & S & R
\end{array}\right]^{T}
$$

The cost function consists of the fuel use and the cost for starting the engine, so:

$$
h=\left[\begin{array}{lllllllll}
0 & 0 & 0 & 0 & 0 & 0 & 1 & 0 & C
\end{array}\right]^{T}
$$

If optimization is done over a horizon of $n$ time steps, the variables are vectors with length $n$, so the total number of design variables is $9 n$.

\section{B. Constraints}

The following constraints are used:

- upper and lower bounds on all design variables

- upper and lower bounds on the energy level of the battery

- an endpoint constraint on the energy level of the battery

- equality constraints for the power flow equations

- inequality constraints for the piecewise linear component characteristics

- inequality constraints for the Start-Stop operation

All constraints are linear in the design variables.

\section{Model Predictive Control}

Because the computation time of mixed integer programming increases rapidly with the number of integer variables, it is not possible to do global optimization over a long driving cycle within a reasonable time. Therefore, the problem is solved using a receding horizon, as in Model Predictive Control (MPC) [8].

This means that the optimization is carried out at each time step over a limited prediction horizon. The first value of the optimal control sequence is implemented. The next time step a new optimization is done using updated prediction and state information.

\section{Removing the endpoint constraint}

For short horizons, the performance of the MPC strategy is limited by the endpoint constraint on the SOC. Therefore, the endpoint constraint is removed and the cost function is modified such that a trade off is made between fuel use and SOC. This approach was presented for a conventional vehicle in [6].

The cost function becomes:

$$
J(x, k)=\sum_{i=k+1}^{k+N_{p}}\left(P_{f}(i)-\lambda P_{s}(i)\right) \Delta t+C R(i)
$$

$N_{p}$ is the length of the prediction horizon. The factor $\lambda$ represents the average fuel cost to store energy in the battery. Its value is adapted online using proportional feedback of the SOC:

$$
\lambda(k)=\lambda_{0}+K_{p}\left(E_{s}(k)-E_{s}(0)\right)
$$

The feedback ensures that the SOC remains bounded, although the SOC at the end may differ from that at the beginning. The difference in SOC can be accounted for in the fuel consumption using the average value of $\lambda$.

\section{Simulation}

Simulations are done for the following strategies:

1) Baseline strategy where the ISG only provides the electric load, like in a conventional vehicle.

2) Optimal strategy with the ISG connected before the clutch without Start-Stop

3) Optimal strategy with the ISG connected before the clutch including Start-Stop

4) Optimal strategy with the ISG connected after the clutch including Start-Stop

The vehicle contains a $60 \mathrm{~kW}$ engine and a $10 \mathrm{~kW}$ (electrical) ISG and a battery with a capacity of $1 \cdot 10^{6} \mathrm{~J}$.

The parameter values of the vehicle model are given in Table II.

Simulations are done for the NEDC cycle, of which the velocity profile and the corresponding engine speed and propulsion power are shown in Fig. 5. The electric load is kept constant at $1000 \mathrm{~W}$.

Optimization is done with a receding horizon length of $10 \mathrm{~s}$. All strategies run faster than realtime on an Intel Pentium IV $2.4 \mathrm{GHz}$ computer. 
TABLE II

PARAMETER VALUES FOR THE SIMULATION MODEL

$\begin{array}{llll}\text { Quantity } & \text { Symbol } & \text { Value } & \text { Unit } \\ \text { Mass } & M & 1400 & \mathrm{~kg} \\ \text { Frontal area } & A_{d} & 2 & \mathrm{~m}^{2} \\ \text { Air friction coefficient } & C_{d} & 0.3 & - \\ \text { Rolling resistance } & C_{r} & 0.015 & - \\ \text { Wheel radius } & w_{r} & 0.3 & \mathrm{~m} \\ \text { Final drive ratio } & f_{r} & 4.0 & - \\ \text { Air density } & \rho & 1.2 & \mathrm{~kg} / \mathrm{m}^{3} \\ \text { Gravity } & g & 9.8 & \mathrm{~m} / \mathrm{s}^{2}\end{array}$
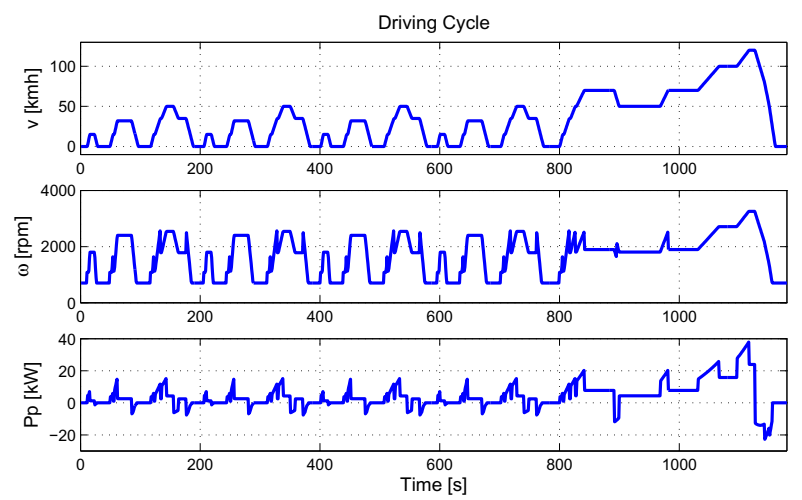

Fig. 5. Driving Cycle

\section{A. Results}

The trajectories of $P_{m}, P_{g}, P_{b r}, S$, and $S O C$ are shown for Strategy 2, 3, and 4 in Fig. 6, Fig. 7, and Fig. 8 respectively. Strategies 2 and 3 use the ISG mainly for regenerative braking and supplying the electric load. Apparently it is not beneficial to use the ISG for propulsion if the engine is already running, but this depends on the selected vehicle and drive cycle. With Strategy 3, the engine is turned off during braking and idle periods.

With Strategy 4, the engine is turned off during low velocity periods and during braking, such that more energy is available for regenerative braking. The engine cannot be turned off when the required propulsion power exceeds the maximum ISG power.

The engine operating points of Strategy 1 and 4 are compared in Fig. 9. As can be seen, Strategy 4 switches between "engine off" and the high torque area, where the efficiency is high, whereas the baseline strategy remains in the low torque area.

\section{B. Fuel consumption}

The fuel savings with respect to Strategy 1 are given in Table III. Differences in SOC are accounted for using $\lambda_{0}$.

Strategies 2 shows a small decrease in fuel consumption because the engine is always running. Profits come mainly from regenerative braking.

Strategy 3 shows a larger fuel reduction, because the engine is turned off during idle periods.

Strategy 4 shows a much higher fuel reduction because it allows turning the engine off during propulsion phases.

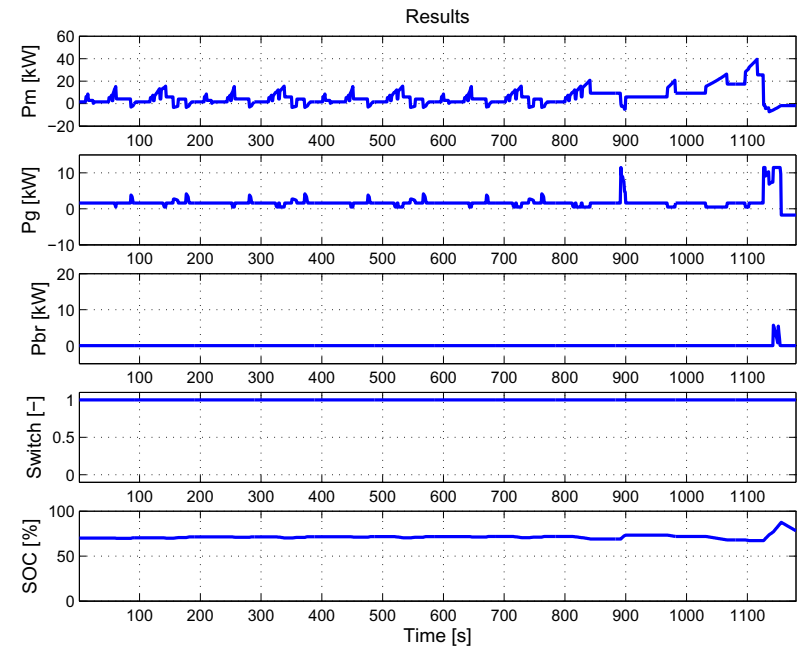

Fig. 6. Results for Strategy 2

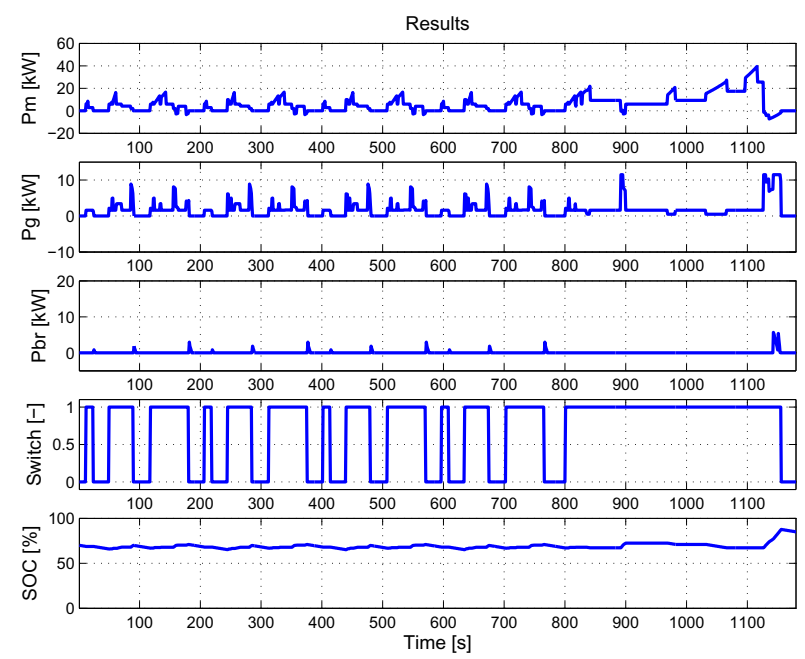

Fig. 7. Results for Strategy 3

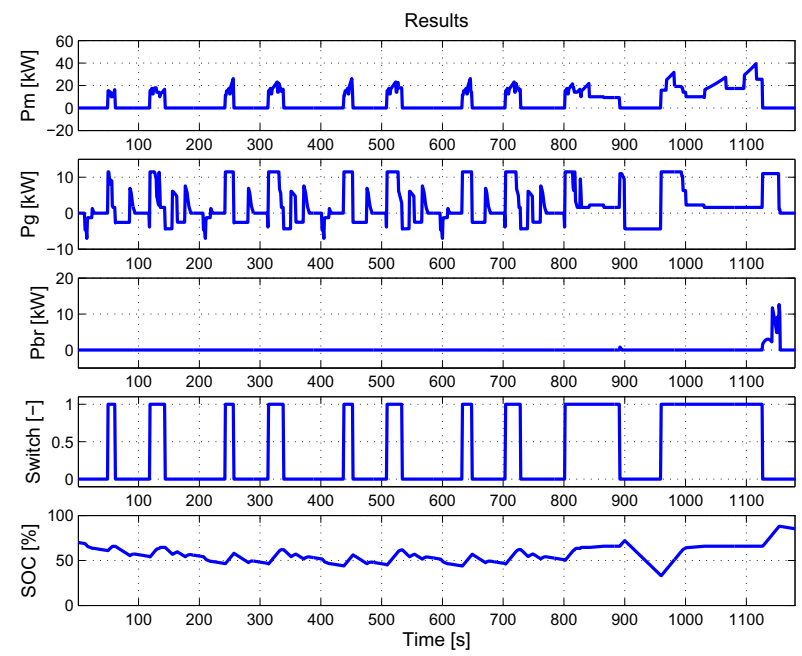

Fig. 8. Results for Strategy 4 


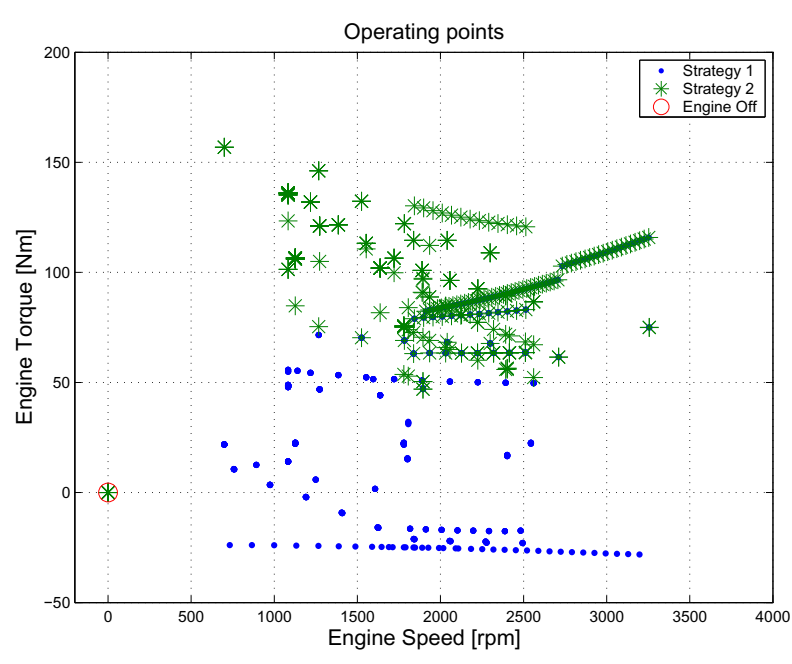

Fig. 9. Operating points

TABLE III

FUEL SAVINGS

\begin{tabular}{llll} 
Strategy & Fuel Use & Fuel Use & Fuel Reduction \\
\hline & $\mathrm{kg}$ & $1 / 100 \mathrm{~km}$ & $\%$ \\
Strategy 1 & 0.698 & 8.53 & - \\
Strategy 2 & 0.686 & 8.38 & 1.76 \\
Strategy 3 & 0.646 & 7.89 & 7.53 \\
Strategy 4 & 0.565 & 6.91 & 19.1
\end{tabular}

\section{Exhaust emissions}

The exhaust emissions $\mathrm{CO}_{2}, \mathrm{CO}, \mathrm{HC}$, and $\mathrm{NO}_{x}$ are also evaluated, although they are not accounted for in the cost function.

$\mathrm{CO}_{2}$ is roughly proportional to fuel consumption, whereas the other emissions are highly non-convex, which makes it harder to incorporate them into a convex LP. Mainly because of Start-Stop operation, they are also reduced significantly, as can be seen in Table IV.

\section{CONCLUSION}

The fuel consumption and exhaust emissions of two parallel hybrid drivetrain configurations are compared: one with the ISG connected directly to the engine, and one with the ISG connected to the drivetrain, after the clutch.
TABLE IV

EXHAUST EMISSIONS

\begin{tabular}{lllll} 
Strategy & $\mathrm{CO}_{2}$ & $\mathrm{CO}$ & $\mathrm{HC}$ & $\mathrm{NO}_{x}$ \\
\hline & $\%$ & $\%$ & $\%$ & $\%$ \\
Strategy 2 & 0.67 & 0.57 & -0.28 & 1.94 \\
Strategy 3 & 7.2245 & 7.1566 & 13.086 & 7.6113 \\
Strategy 4 & 21.875 & 18.724 & 39.423 & 17.378
\end{tabular}

The simulations show a large improvement in fuel and emissions reduction if Start-Stop is included, especially if the ISG is placed after the clutch.

The results depend on the component sizing and the driving cycle. More improvement can possibly be obtained by including freedom in the engine speed.

The optimization is done using a short receding horizon, so the method allows easy real time implementation. Due to the choice of cost function (36), the results are expected to be close to the global optimum.

Finally, Linear Programming is a powerful tool for this application. Because of its simple structure, the method is easy to apply to other topologies.

\section{REFERENCES}

[1] K.G. Murty. Linear Programming. John Wiley \& Sons, New York, 1983.

[2] E.D. Tate and S.P. Boyd. Finding ultimate limits of performance for hybrid electric vehicles. In Proc. of the SAE Future Transportation Technology Conf., Costa Mesa, CA, August 2000. SAE Paper 2000-01-3099.

[3] D.P. Bertsekas. Dynamic Programming and Optimal Control. Athena Scientific, Belmont, MA, 1995.

[4] C.-C. Lin, H. Peng, J.W. Grizzle, and J.-M. Kang. Power management strategy for a parallel hybrid electric truck. IEEE Trans. on Control Systems Technology, 11(6):839-849, November 2003.

[5] M. Desbois-Renaudin, R. Trigui, and J. Scordia. Hybrid powertrain sizing and potential consumption gains. In Proc. of the IEEE VTS Symposium on Vehicular Power And Propulsion, Paris, France, October 2004.

[6] M. Koot, J.T.B.A. Kessels, B. de Jager, W.P.M.H. Heemels, P.P.J. van den Bosch, and M. Steinbuch. Energy management strategies for vehicular electric power systems. IEEE Trans. on Vehicular Technology, 54(3):771-782, May 2005.

[7] M. Koot, J. Kessels, and B. de Jager. Energy management in a vehicle with a dual storage power net. In Proc. of the 16th IFAC World Congress, Prague, Czech Republic, July 2005.

[8] J.M. Maciejowski. Predictive Control with Constraints. Prentice Hall, 2001. 